Article

\title{
Experimental Study on the Effects of Air Supply Control on Combustion and Emissions Performance at Medium and Low Load for a Dual-Fuel Diesel Engine
}

\author{
Yu-Hui Peng ${ }^{1, *} \mathbb{0}$, Yu-Peng Huang ${ }^{1}$, Jia-You Tang ${ }^{1}$, Qi-Feng Huang ${ }^{1,2}$ and Yi-Ran Huang ${ }^{3}$ \\ 1 School of Mechanical Engineering and Automation, Fuzhou University, Fuzhou 350116, China; \\ N160220071@fzu.edu.cn (Y.-P.H.); N170227098@fzu.edu.cn (J.-Y.T.); N180220069@fzu.edu.cn (Q.-F.H.) \\ 2 Department of Mechanical and Electrical Engineering, Longyan University, Longyan 364012, China \\ 3 Fujian Lijia Co., Ltd., Zhangzhou 363006, China; jszx@lijia.com.cn \\ * Correspondence: pengyuhui@fzu.edu.cn; Tel.: +86-185-5916-0365
}

Received: 21 September 2018; Accepted: 26 October 2018; Published: 29 October 2018

\begin{abstract}
Lowering the amount of excess air is believed to increase the density of the air-fuel mixture and help improve the combustion rate for compression ignition engines. This paper proposes an approach of adding a throttle body at the intake pipe to control the excess air ratio with reduction of air supply to achieve a better balance between the power, emissions and fuel efficiency at medium and low load of a natural gas dual-fuel diesel engine converted from a conventional diesel engine. Various experiments in both pure diesel and dual-fuel mode under intermediate engine speed are performed with the proposed critical method of excess air ratio control. The experimental results reveal that better excess air ratio is very beneficial for the power output and brake specific energy consumption in dual-fuel combustion under medium and low load conditions. Moreover, the substitution rate can reach as high as $40 \%$ under low load conditions with throttle control.
\end{abstract}

Keywords: excess air ratio; dual-fuel engine; natural gas; substitution rate; bench test

\section{Introduction}

Natural gas (NG) is considered as one of the three main sources of energy along with coal and oil and plays an essential role in the world's energy supply. Thanks to the merit of high intrinsic $\mathrm{H} / \mathrm{C}$ ratio, high auto-ignition temperature and superior resource availability at attractive prices, NG is widely recognized as one of the most promising clean alternative fuels for conventional diesel engines. Therefore, the usage of NG dual-fuel diesel engines retrofitted from diesel engines has been focused on to improve fuel economy and reduce exhaust gas emissions [1-3]. In general, the diesel fuel supply system remains unchanged and provides the pilot diesel to ignite the NG-air mixture in the combustion chamber. The engine power output is directly controlled by the amount of fuel admitted to the cylinder without a throttle valve along the intake pipe. Usually, for reasons of both emissions and fuel economy, the main purpose of development of NG dual-fuel diesel engines is to maximize the use of cheaper NG instead of diesel fuel over the whole range of engine loads [4].

Numerous studies have revealed that the dual-fuel combustion application has significantly positive low soot and NOx emissions, comparable power output and fuel cost in comparison with diesel engines. However, the negative features of lower combustion efficiency, carbon monoxide (CO) and unburned hydrocarbon (HC) emissions, especially under medium and low load also have been pointed out. In operations at low load, a small amount of fuel is required, and the amount 
of air supplied is only determined by the engine speed under unthrottled operation conditions. Therefore, too lean an air-fuel mixture owing to air oversupply results in difficult mixture ignition and flame propagation, which leads to unstable combustion, deterioration of fuel efficiency and high emissions of unburned hydrocarbons and carbon monoxide. In order to solve the mentioned issues, the effects of varying the intake temperature and pilot diesel injection mass on the onset of ignition and combustion for a single-cylinder engine were investigated to show that engine performance, stability, and emissions were more strongly affected by the intake charge temperature compared to pilot injection mass at low loads [5]. The effects of pilot injection timing, pilot injection pressure and NG injection timing on the combustion performance and emissions for a four-cylinder turbocharged diesel engine with common rail injection at low load operations have been analyzed, and the results indicated that retarded natural gas injection timing can represent an effective method to improve the combustion performance and exhaust emissions at low load [6]. A split injection strategy for the diesel pilot to increase the in-cylinder peak pressure and thermal efficiency at low loads by an experimental and numerical study were described [7]. At the same time, a split injection strategy provided an effective approach to accomplish the trade-off between $\mathrm{NOx}-\mathrm{CH}_{4}$ and $\mathrm{NOx}-\mathrm{CO}$ emissions [7]. The influences of methane substitution ratio, the usage of exhaust gas recirculation (EGR) and pilot injection strategy on engine performance and emissions at low loads were studied in [8], and the study reported that the increase of methane substitution ratio obviously contributed to the high level of $\mathrm{HC}$ and $\mathrm{CO}$ emissions, the lower combustion rate and the lower combustion efficiency at low loads. The study of optimal operation strategies for the equivalence ratio of NG-air mixture and EGR rate at low loads was focused on, and the results revealed that it was impossible to run the engine with low emissions of $\mathrm{CO}_{2}$ and HC simultaneously under low load conditions [9]. In addition, studies on the effects of pilot injection timing $[10,11]$, and compression ratio $[12,13]$ at low loads have been also described.

Based on the observation of the studies mentioned above, it is noteworthy that the status of in-cylinder air-fuel mixture is primarily affected by NG substitution rate, pilot diesel injection mass, EGR rate and the amount of air supply determines the combustion process when the timings of fuel injection are fixed. As to the natural gas port injection dual-fuel engines, most studies rely on the unthrottled operation strategy to achieve the benefits of lower pumping loss and high volumetric efficiency. Factually, lowering the amount of excess air with throttle control effectively enables one to increase in-cylinder average mixture temperature and improve flame propagation [3], which provides an effective approach to improve the excess air ratio and engine performance. Moreover, to better control the excess air ratio a few studies on NG dual-fuel diesel engines have been reported to obtain proper air-fuel ratio regulation with control of the throttle opening $[8,10,14-18]$. Unfortunately, little research has been done to extensively explore the effects of adjusting the excess air ratio on the dual-fuel combustion under light load. In particular, the loss of volumetric efficiency resulting from throttled control will lower the in-cylinder temperature and compression pressure at the same time [19]. Therefore, it's necessary to explore how to achieve a balance between the requirements of better air-fuel ratio and volumetric efficiency for the NG dual-fuel diesel engine under medium and low loads. Moreover, finding a NG substitution rate as high as possible with throttled control needs more attention through an extensive investigation.

In this study, to pursue possible high NG substitution rates at medium and low loads, the authors propose an approach of adding a throttle body at the intake pipe to control the excess air ratio of the air-fuel mixture to achieve a better balance between the power, emissions and fuel efficiency. In consequence, experimental investigations on various operations with throttled control are implemented. The NG diesel dual-fuel engine applied in this study is retrofitted from a non-road two-cylinder diesel engine running with an electronic unit pump injection system. The excess air ratio is adjusted through throttle opening, pilot diesel injection and NG injection with constant speed. Based on bench tests, the combustion performance and emissions are compared under various operating modes, including conventional diesel mode (or pure diesel), and dual-fuel mode with 
different substitution rates under medium and low load. The ultimate aim of this study is to provide guidance for optimizing the fuel supply strategy for dual-fuel engines at medium and low loads.

\section{Experimental Setup and Procedure}

\subsection{Experimental Apparatuses}

The NG diesel dual-fuel engine used in this experiment is retrofitted from a non-road two-cylinder naturally aspirated SL2110DKT-3 diesel engine and its specifications are shown in Table 1.

Table 1. Engine specifications.

\begin{tabular}{cc}
\hline Engine Specifications & Value \\
\hline Rated power $/ \mathrm{kW}$ & 25.7 \\
Rated speed $/ \mathrm{rpm})$ & 2400 \\
Compression ratio & 17 \\
Displacement $/ \mathrm{L}$ & 2.224 \\
Bore $\times$ Stroke $/ \mathrm{mm}$ & $110 \times 117$ \\
Connecting rod length $/ \mathrm{mm}$ & 185 \\
Inlet valve opening $/ \mathrm{closing} /{ }^{\circ} \mathrm{CA}$ & 12BTDC $/ 44 \mathrm{ABDC}$ \\
Exhaust valve opening $/$ closing $/{ }^{\circ} \mathrm{CA}$ & 52BBDC $/ 12 \mathrm{ATDC}$ \\
\hline
\end{tabular}

The framework of our dual-fuel engine test bench system is displayed in Figure 1. It is noteworthy that a throttle body is installed additionally at the intake pipe to control the air flow. Ahead of the throttle body, a model Toceil-OMFGO25 air flowmeter (Shanghai ToCeil Engine Testing Equipment, Shanghai, China) is mounted to obtain the dynamic air flow. The NG supply system consisted of a LNG tank, vaporizer, filter, solenoid on-off switch, regulator, gas flow meter, buffer tank, rail and injectors in sequence. The presence of a buffer tank between rail and flow meter enabled us to effectively stabilize the working pressure of the rail and the outlet pressure of the flow meter, thereby improving the NG injection accuracy. For each cylinder, the NG is injected into the inlet manifold by an independent injection valve, which is mounted on the rail. Two hoses are used to connect the injectors and inlet ports on manifold independently. In this way, the dynamic flow of NG is detected by a M250S flow meter (Alicat Scientific Inc., Tucson, AZ, USA) with a maximum working frequency of $100 \mathrm{~Hz}$, reflecting the real NG injection. Besides, to detect the real-time in-cylinder pressure, a high-temperature pressure sensor $(6052 \mathrm{C}$, Kistler, Winterthur, Switzerland) is installed in the first cylinder, and the diesel consumption is measured by a CMFD010 diesel mass flow-meter (Shanghai ToCeil Engine Testing Equipment). No changes are made to the diesel delivery system. Additionally, the variables of engine torque and rotation speed are measured with a DW63 engine dynamometer (Chengbang Science \& Technology, Chengdu, China), and temperatures of both coolant and lubricating oil are controlled automatically by an ET2900-1cooling system (Chengbang Science \& Technology). The level of exhaust emissions of $\mathrm{CO}, \mathrm{CO}_{2}, \mathrm{HC}$, NOx and soot are measured by an Infralyt ELD V347 exhaust gas analyzer (SAXON Junkalor GmbH, Dessau-Roßlau, Germany), and an FTY-100 Opacimeter smoke meter (Foshan Analytical Instrument, Foshan, China), respectively. Under the help of ECKA V2 engine calibration software (Changzhou Automotive Electronic System, Changzhou, China), the engine can be operated in dual-fuel mode or pure diesel mode smoothly with the control of pilot diesel injection timing, NG injection timing, pilot diesel quantity, NG injection quantity, and the throttle opening. The specifications and precision of instruments involved in this study are listed in Table 2.

In order to ensure the accuracy and reliability of measurement, the measuring range and accuracy of concerned instruments are carefully selected and calibrated before bench tests. Specifically, the exhaust gas analyzer is calibrated with the respective standard gases of $\mathrm{C}_{3} \mathrm{H}_{8}, \mathrm{NO}, \mathrm{CO}$ and $\mathrm{CO}_{2}$ and the smoke meter is calibrated by test glass slides of different opacity values $(10 \%, 30 \%, 50 \%$, etc.). Additionally, the specification of torque can be calibrated manually in the requested range based on lever balance theory. The throttle connecting to the control system of dynamometer can be calibrated 
in the opening range of $0-100 \%$. The diesel flow-meter, air flow-meter, natural gas flow-meter and pressure sensor instruments are calibrated periodically by the manufacturer.

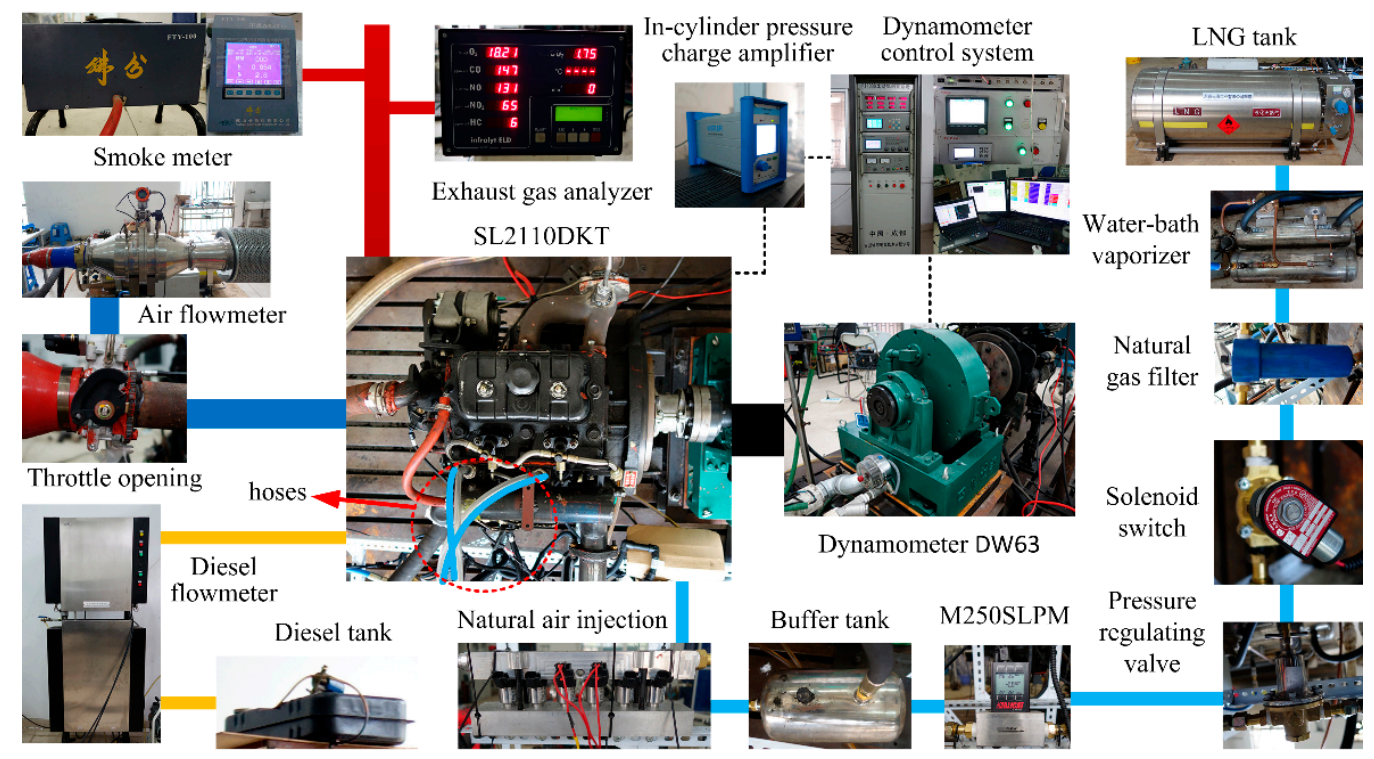

Figure 1. Dual-fuel engine test bench system.

Table 2. Main instruments for experiments.

\begin{tabular}{ccc}
\hline Item & Specification & Precision \\
\hline Dynamometer & Torque N·m & $\pm 0.4 \%$ F.s \\
& Rotation Speed rpm & $0.1 \% \pm 1$ \\
\hline Diesel flow-meter & Fuel mass flow $\mathrm{Kg} / \mathrm{h}$ & $\pm 0.12 \%$ \\
Air flow-meter & Volumetric flow rate $\mathrm{m}^{3} / \mathrm{h}$ & $\pm 0.5 \%$ \\
Natural gas flow-meter & Volumetric flow rate SLPM & $\pm 0.8 \%$ \\
Pressure sensor & In-cylinder pressure bar & $\leq \pm 0.5$ \\
\hline & Volume percent of $\mathrm{CO}$ ppm & 10 \\
& Volume percent of $\mathrm{CO}_{2} \%$ & \pm 0.4 \\
Exhaust gas analyzer & Volume percent of $\mathrm{HC} \mathrm{ppm}$ & \pm 10 \\
& Volume percent of $\mathrm{NO}_{\mathrm{ppm}}$ & \pm 12 \\
& Volume percent of $\mathrm{NO}_{2} \mathrm{ppm}$ & \pm 5 \\
\hline Smoke meter & Smoke opacity $\%$ & \pm 0.1 \\
\hline
\end{tabular}

\subsection{Experimental Procedure}

The main goal scope of this study was to investigate the effects of different NG substitution rates on engine performance and emissions with control of the fixed excess air ratio at medium and low load under the condition of constant energy input at the same load and a constant speed of $1600 \mathrm{rpm}$. The excess air ratio is controlled through the method detailed in Section 2.3. The total energy input is determined by diesel consumption of the corresponding operation in pure diesel mode. The conventional diesel operation experiments are conducted after engine warm-up to arrive at a steady state when the coolant temperature reaches $50{ }^{\circ} \mathrm{C}$ and revolution speed varies within $2 \mathrm{rpm}$ and torque output varies within $0.1 \mathrm{~N} \cdot \mathrm{m}$. All tests are carried out under a constant coolant temperature of around $85^{\circ} \mathrm{C}$ and a lubricating oil temperature of around $75^{\circ} \mathrm{C}$. Besides the conventional diesel operations, experiments of dual-fuel working conditions with NG substitution rates of $20 \%, 40 \%$, $60 \%$ and $80 \%$ are implemented under constant speed $(1600 \mathrm{rpm})$ at low load $(27.1 \mathrm{~N} \cdot \mathrm{m})$ and medium load $(50.6 \mathrm{~N} \cdot \mathrm{m})$. The speed of $1600 \mathrm{rpm}$ as intermediate speed is chosen according to the regulation of GB20891-2014 [20], and the rated torque at speed of $1600 \mathrm{rpm}$ is $120 \mathrm{~N} \cdot \mathrm{m}$. Therefore, the load of 
$27.1 \mathrm{~N} \cdot \mathrm{m}$ and $50.6 \mathrm{~N} \cdot \mathrm{m}$ represents well the working conditions of low load $(22.5 \%)$ and medium load $(42.2 \%)$. To evaluate the suggested approach, the characteristics of power output, indicated thermal efficiency (ITE), brake specific energy consumption (BSEC), exhaust of soot and gaseous emissions are introduced in this study. During all the experiments with $1600 \mathrm{rpm}$ engine speed, timing of the diesel injection and NG injection is fixed at $16{ }^{\circ} \mathrm{CA}$ BTDC and $300{ }^{\circ} \mathrm{CA}$ BTDC respectively.

\subsection{Method of Excess Air Ratio Control}

\section{Substitution rate}

The NG substitution rate herein is defined as a reduction of diesel fuel injection replaced by amount of NG with the same heat value, a mass ratio of the decrease of diesel fuel injection in dual-fuel operation mode divided by the diesel consumption in conventional diesel mode under the same working conditions [21,22]:

$$
R=\frac{m_{d 1}-m_{d 2}}{m_{d 1}} \times 100 \%
$$

where $R$ is the NG substitution rate, $m_{d 1}$ is the amount of diesel supply in the conventional diesel mode $(\mathrm{mg})$ measured by the diesel flow-meter; $m_{d 2}$ is the pilot diesel injection mass in the dual-fuel mode (mg), which is controlled by the ECKA engine calibration system and measured by the diesel flow-meter. Therefore, the pilot diesel injection mass $m_{d 2}$ at the dual-fuel mode also can be calculated practically by use of Equation (1) as $m_{d 1}$ was measured and $R$ was preset before the experiment. It must be noted that varying the NG substitution rate $R$ means a different mass fraction of pilot diesel $m_{d 2}$ and NG at the same working point. NG substitution rate $R$ plays a critical role on the excess air ratio control in the following explanation.

\section{Fuel properties}

The fuels mainly consist of $\mathrm{C}$ and $\mathrm{H}$ as shown in Table 3, and the content of other elements is very low and can be ignored [23].

Table 3. Fuel properties.

\begin{tabular}{|c|c|c|c|}
\hline & & Diesel & Natural Gas \\
\hline \multicolumn{2}{|c|}{ Chemical formula } & $\mathrm{C}_{\mathrm{n}} \mathrm{H}_{\mathrm{m}}$ & $\mathrm{CH}_{4}$ \\
\hline \multirow{2}{*}{ component quality } & $\mathrm{g}_{\mathrm{C}} / \mathrm{kg}$ & 0.847 & 0.750 \\
\hline & $\mathrm{g}_{\mathrm{H}} / \mathrm{kg}$ & 0.126 & 0.250 \\
\hline \multicolumn{2}{|c|}{ molecular mass } & $180 \sim 200$ & 16 \\
\hline \multicolumn{2}{|c|}{ stoichiometric } & 14.3 & 17.4 \\
\hline LHV & $\mathrm{kJ} / \mathrm{kg}$ & 42,500 & 50,050 \\
\hline Heat value at $\phi_{a}=1$ & $\mathrm{~kJ} / \mathrm{m}^{3}$ & 3750 & 3230 \\
\hline
\end{tabular}

The amounts of $\mathrm{C}$ and $\mathrm{H}$ of diesel are $0.847 \mathrm{~g}_{\mathrm{C}} / \mathrm{kg}$ and $0.126 \mathrm{~g}_{\mathrm{H}} / \mathrm{kg}$, respectively, and the molecular formula of diesel is $\mathrm{CH}_{1.73}$. When the fuel is completely burned with $\mathrm{O}_{2}$, the chemical reaction for generating $\mathrm{CO}_{2}$ and $\mathrm{H}_{2} \mathrm{O}$ is as follows:

$$
x \mathrm{CH}_{1.73}+y \mathrm{CH}_{4}+(1.4325 x+2 y) \mathrm{O}_{2}=(x+y) \mathrm{CO}_{2}+(0.865 x+2 y) \mathrm{H}_{2} \mathrm{O}
$$

where $x$ is the amount (mol) of the completely burned diesel $\left(\mathrm{CH}_{1.73}\right)$ and $y$ is the molar amount of the completely burned $\mathrm{NG}\left(\mathrm{CH}_{4}\right)$ showed in the following expression:

$$
\begin{gathered}
x=m_{d 1} \cdot(1-R) / M_{\mathrm{CH}_{1.73}} \\
y=R \cdot m_{d 1} \cdot H_{\mathrm{d}} / H_{\mathrm{NG}} / M_{\mathrm{CH}_{4}}
\end{gathered}
$$


where $M_{\mathrm{CH}_{1.73}}$ is the mole mass of diesel $(13.73 \mathrm{~g} / \mathrm{mol})$ and $H_{\mathrm{d}}$ is the low heat value of diesel $(42,500$ $\mathrm{kJ} / \mathrm{kg})$, and $H_{\mathrm{NG}}$ is the low heat value of NG $(50,050 \mathrm{~kJ} / \mathrm{kg})$, and the NG mass is $16 \mathrm{~g} / \mathrm{mol}$, and the total amount (mol) of oxygen involved is $1.4325 x+2 y$. It must be noticed that the amount of NG combustion is computed by the same total heat value of replaced diesel according to Equation (4). Therefore, considering definition of NG substitution rate in Equation (1), different substitution rates means different fuel fractions of NG and diesel with the same total energy input due to the same $m_{\mathrm{d} 1}$.

Since the mass ratio of nitrogen to oxygen in the air is 0.77:0.23, the theoretical amount of air required for complete combustion of diesel and natural gas is expressed in Equation (5):

$$
m_{\text {air-t }}=n_{\mathrm{O}_{2}} \times \mathrm{M}_{\mathrm{O}_{2}} / 0.23=m_{d 1} \cdot(14.49+0.2518 R)
$$

where $m_{\text {air }-t}$ is the amount of air $(\mathrm{g})$ and $n_{\mathrm{O}_{2}}$ is the oxygen mass (mol) and $M_{\mathrm{O}_{2}}$ is the molar mass of oxygen, equal to $32 \mathrm{~g} / \mathrm{mol}$.

3. Excess air ratio of dual-fuel combustion $\left(\phi_{a}\right)$

When the air-fuel mixture of diesel and NG is mixed with stoichiometric ratio, the amount of air demanded theoretically to completely burn the fuel is noted as $m_{\text {air }-t}=14.3 m_{d 1} \times(1-R)+17.4 m_{N G}$, and the excess air ratio $\phi_{a}$ can also be expressed as follows:

$$
\phi_{a}=\frac{\phi_{a} \cdot m_{d 1} \cdot(14.49+0.2518 R)}{14.3 m_{d 1} \cdot(1-R)+17.4 m_{N G}}
$$

where $m_{\mathrm{NG}}$ is the mass of the NG supply $(\mathrm{mg})$, and $\phi_{a} \cdot m_{d 1} \cdot(14.49+0.2518 R)$ is considered as the target amount of air supply, denoted as $m_{\text {air }}$, which is determined actually by the engine speed and throttle opening. In the other hand, $m_{\text {air }}$ also can be calculated theoretically as a target amount of air supply if $m_{d 1}$ was measured and $\mathrm{R}$ was selected and $\phi_{a}$ was determined. The deduction of Equation (6) validates the target NG supply as follows:

$$
m_{\mathrm{NG}}=m_{d 1} \times(0.01092+0.8363 R)
$$

4. Minimal throttle opening, reference amount of air supply $\left(m^{\prime}\right.$ air $)$ and reference excess air ratio $\left(\phi_{a}^{\prime}\right)$

To reduce the negative influence of lower volumetric efficiency, the minimal throttle opening at the operation involved is achieved by the following procedure. Firstly, the engine is kept running in conventional diesel mode at a certain condition with fully opened throttle. Then, the throttle opening is adjusted gradually from fully open to closed status while the engine speed, torque output and diesel injection remains unchanged under the control of the dynamometer system. With the gradual decreasing of throttle opening, a drop of engine torque output emerges, as shown in Figure 2. The throttle opening corresponding to the inflection point on the power curve is obtained as the minimal throttle opening related to the working conditions. For the operations of $1600 \mathrm{rpm}, 27.1 \mathrm{~N} \cdot \mathrm{m}$ and $1600 \mathrm{rpm}, 50.6 \mathrm{~N} \cdot \mathrm{m}$, the respective minimal throttle openings are $29.2 \%$ and $41.4 \%$, and the reduction of air supply is $177.91 \mathrm{mg} /$ cylinder.cycle and $84.18 \mathrm{mg} /$ cylinder.cycle compared to that in full throttle opening mode. Due to the fact there is almost no change of engine speed and torque output at this moment, the improvement of excess air ratio and reduction of volumetric efficiency is considered to reach a sound balance. The amount of air supply at this moment is measured as the reference amount of air supply $m^{\prime}{ }_{\text {air }}$. Consequently, each reference excess air ratio related to the corresponding operation with different NG substitution rate can be practically calculated according to Equation (8) since other variables in the equation are known:

$$
\phi_{a}^{\prime}=\frac{m_{a i r}^{\prime}}{m_{d 1} \times(14.49+0.2518 R)}
$$




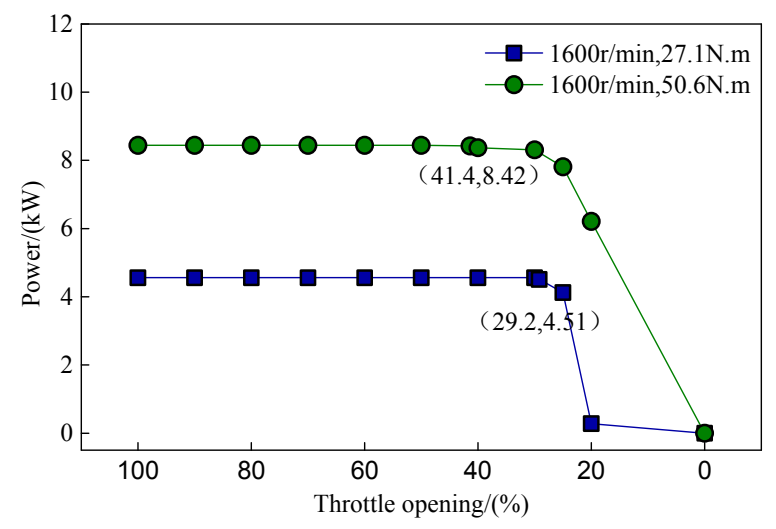

Figure 2. Power outputs with different throttle opening.

The values of concerned parameters are listed in Table 4 . The above tasks should be carefully done before the dual-fuel combustion test.

5. Target excess air ratio $\left(\phi_{a}\right)$

The target excess air ratio $\phi_{a}$ is defined as the average value of all $\phi_{a}^{\prime}$ at the same speed and load condition, and it provides the base value to estimate and control the amount of target NG supply for dual-fuel operations (see Table 5). The NG supply is calculated by use of Equation (7). For each working point with a different NG substitution rate, since $\mathrm{R}, m_{d 2}, m_{d 1}, \phi_{a}$, and the amount of NG supply are ascertained, according to the definition of $m_{\text {air }}$ in Equation (6) it's convenient to govern the actual air supply only by adjusting the throttle opening to commit the target excess air ratio $\phi_{a}$ under the measurement of air flow-meter. It should be noticed that the throttle is adjusted in a slight wide opening to compensate the influence of increasing NG supply as the NG substitution rate arises compared to the conventional diesel operation during the dual-fuel experiment process.

Table 4. Parameters' values used in dual-fuel experiments.

\begin{tabular}{|c|c|c|c|c|c|c|}
\hline Experiment Case & $\begin{array}{c}m_{d 1} \\
\mathrm{mg} /(\text { cylinder } \cdot \text { cycle })\end{array}$ & R \% & $\begin{array}{c}m_{d 2} \\
\mathrm{mg} /(\text { cylinder } \cdot \text { cycle) }\end{array}$ & $\begin{array}{c}m^{\prime}{ }_{\text {air }} \\
\mathrm{mg} /(\text { cylinder} \cdot \text { cycle })\end{array}$ & $\phi_{a}^{\prime}$ & $\phi_{a}$ \\
\hline \multirow{4}{*}{$\begin{array}{l}1600 \mathrm{rpm} \\
27.1 \mathrm{~N} \cdot \mathrm{m}\end{array}$} & \multirow{4}{*}{19.69} & 20 & 1.51 & \multirow{4}{*}{935.42} & 3.2677 & \multirow{4}{*}{3.25} \\
\hline & & 40 & 1.13 & & 3.2564 & \\
\hline & & 60 & 0.76 & & 3.2452 & \\
\hline & & 80 & 0.38 & & 3.2341 & \\
\hline \multirow{4}{*}{$\begin{array}{l}1600 \mathrm{rpm} \\
50.6 \mathrm{~N} \cdot \mathrm{m}\end{array}$} & \multirow{4}{*}{31.04} & 20 & 2.38 & \multirow{4}{*}{1026.04} & 2.2732 & \multirow{4}{*}{2.26} \\
\hline & & 40 & 1.79 & & 2.2654 & \\
\hline & & 60 & 1.19 & & 2.2576 & \\
\hline & & 80 & 0.60 & & 2.2499 & \\
\hline
\end{tabular}

Table 5. Target air supply and NG supply.

\begin{tabular}{ccccc}
\hline Experiment CASE & $\begin{array}{c}\text { Substitution } \\
\text { Rate } \%\end{array}$ & Excess Air Ratio & $\begin{array}{c}\text { Target Air } \\
\text { Supplymg/(cylinder·cycle) }\end{array}$ & $\begin{array}{c}\text { Target NG Supply } \\
\text { mg/(cylinder·cycle) }\end{array}$ \\
\hline \multirow{2}{*}{$1600 \mathrm{rpm}$} & 20 & & 930.36 & 3.51 \\
$27.1 \mathrm{~N} \cdot \mathrm{m}$ & 40 & 3.25 & 933.58 & 6.80 \\
$(4.54 \mathrm{~kW})$ & 60 & & 936.80 & 10.09 \\
& 80 & & 940.02 & 13.39 \\
\hline \multirow{2}{*}{$1600 \mathrm{rpm}$} & 20 & & 1020.07 & 5.53 \\
$50.6 \mathrm{~N} \cdot \mathrm{m}$ & 40 & 2.26 & 1023.60 & 10.72 \\
$(8.48 \mathrm{~kW})$ & 60 & & 1027.13 & 15.92 \\
& 80 & & 1030.67 & 21.11 \\
\hline
\end{tabular}




\section{Results and Discussion}

\subsection{Power Output}

The comparison of brake power output at different substitution rates is shown in Figure 3. At low load operations as $\phi_{a}$ equals to 3.25 , the power is increased by $0.17 \mathrm{~kW}(3.7 \%)$ at substitution rates of $20 \%$ and reduced by $0.26 \mathrm{~kW}(5.7 \%)$ at substitution rates of $40 \%$ compared to that of pure diesel operation. As shown in Figure 4, the combustion phasing is retarded and the peak in-cylinder pressure decreases with the increase of substitution rate, especially at $80 \%$ substitution rate which was observed previously [24,25]. It can be explained that too lean a mixture and a smaller pilot diesel injection slow down the burn rate and most of the NG-air mixture is burned in the post-combustion period during the expansion stroke as the instantaneous heat release rate (HRR) trace expresses the same phenomenon with increasing substitution rate [26]. At low load, the substitution rate can reach as high as $40 \%$ and the reduction of power output is controlled at $5.7 \%$ less than the target power requirement with throttled control. This seems to attain an acceptable improvement of the substitution rate since no more than $30 \%$ of NG mass percentage is suggested by previous studies without throttle control at low load [8].

At medium load, the engine power output in dual-fuel mode is boosted overall with an average value of $0.94 \mathrm{~kW}(11.1 \%)$ compared to that of pure diesel operation. The ignition delay is prolonged with the increase of substitution rate are shown in Figure 5 as $\phi_{a}$ equals to 2.26. At a substitution rate of $20 \%$, the in-cylinder pressure curve is quite close to that of the pure diesel mode. However, in the slow combustion period, the in-cylinder pressure curve appears to be obviously serrated, which indicates that the in-cylinder pressure fluctuates greatly and the combustion in the cylinder seems to be coarse and explosive. The reasons for this are still unknown. Obviously, at medium load conditions, a high substitution rate can be achieved to meet the requirement of power output considering greater power of $0.13 \mathrm{~kW}(1.5 \%)$ compared to the pure diesel operation is declared at $80 \%$ substitution rate.

The indicated thermal efficiency (ITE) of the engine at each operating condition is described in Table 6. ITE, as an indicator of energy conversion efficiency, is computed by the indicated power divided by total heat content of the injected fuel (NG and diesel), and the indicated power is calculated through the accumulated area covered in the P-V diagram derived from the in-cylinder pressure data with an interval resolution of $0.2^{\circ}$ crank angle (CA). ITE at the target operating point (1600 rpm, $27.1 \mathrm{~N} \cdot \mathrm{m})$ and $(1600 \mathrm{rpm}, 50.6 \mathrm{~N} \cdot \mathrm{m})$ in the pure diesel mode are computed as $28.47 \%$ and $28.13 \%$, respectively, with full opening of the throttle (without control of air supply). Under dual-fuel working conditions, ITE is promoted with the increase of substitution rate. Previous work pointed out that delayed ignition helps to form more fuel-air mixture before the start of combustion, which favors the formation of the ignition kernel [7]. Herein, as the HRR profiles show in Figures 4 and 5, the ignition delay is delayed and combustion phasing is retarded because of the smaller pilot diesel injection with the increase of substitution rate. In view of the fact most of the NG-air mixture is burned during the expansion stroke, fuel utilization may be deteriorated. However, at the operation of $80 \%$ substitution rate and low load, although the ITE increased by $8.16 \%$, its brake power output is decreased by $75.88 \%$ compared to those of pure diesel combustion without throttled control in Figure 3 . The reasons can be explained by the fact that because the heat release in the post-combustion period is far away from the TDC, the energy can't be converted usefully. Furthermore, as the piston moves downward the increase of chamber surface leads to more heat loss, deteriorating the fuel economy [23]. 


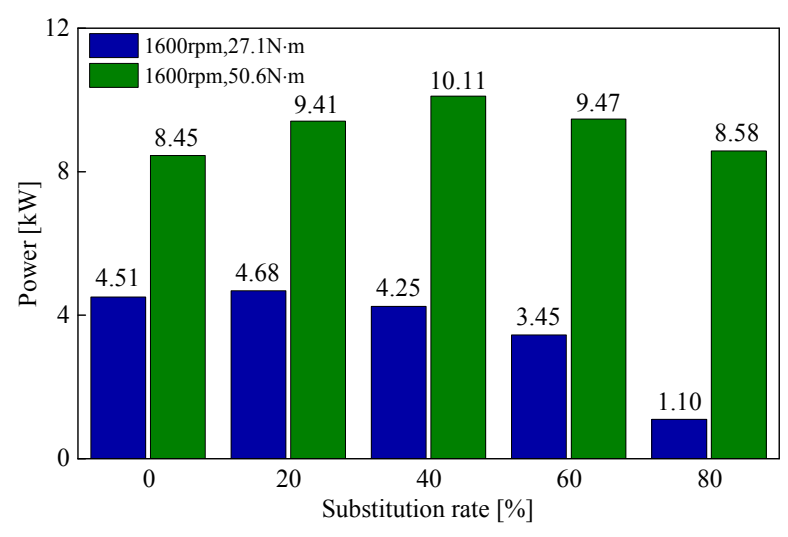

Figure 3. Power outputs with different substitution rate under throttled operation.

Table 6. Indicated thermal efficiency at different conditions and substitution rate.

\begin{tabular}{|c|c|c|c|c|c|c|c|c|c|c|}
\hline \multirow{2}{*}{$\begin{array}{c}\text { Specification/Unit } \\
\text { Torque output/N.m }\end{array}$} & \multicolumn{5}{|c|}{$1600 \mathrm{rpm} 27.1 \mathrm{~N} \cdot \mathrm{m}$} & \multicolumn{5}{|c|}{$1600 \mathrm{rpm} 50.6 \mathrm{~N} \cdot \mathrm{m}$} \\
\hline & 26.97 & 27.90 & 25.40 & 20.60 & 6.57 & 50.47 & 56.20 & 60.40 & 56.63 & 51.30 \\
\hline Substitution rate/\% & 0 & 20 & 40 & 60 & 80 & 0 & 20 & 40 & 60 & 80 \\
\hline icated ther & 27.73 & 29.20 & 33.34 & 35.86 & 36.63 & 27.91 & 30.84 & 32.06 & 35.24 & 37.79 \\
\hline Difference of thermal efficiency /\% & -0.74 & 0.73 & 4.87 & 7.39 & 8.16 & -0.22 & 2.71 & 3.93 & 7.11 & 9.66 \\
\hline
\end{tabular}

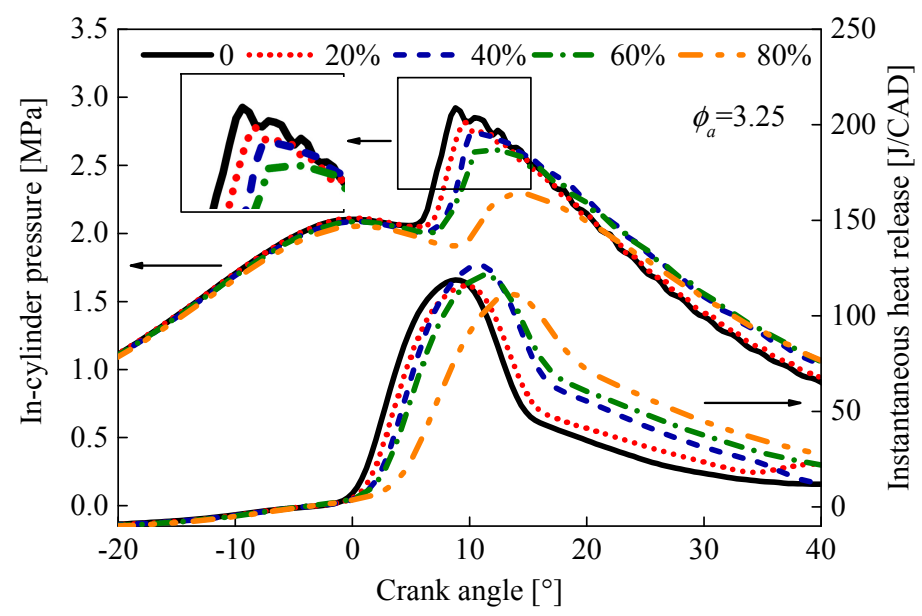

Figure 4. Comparison of in-cylinder pressure and HRR under different substitution rates at $\phi_{a}=3.25$.

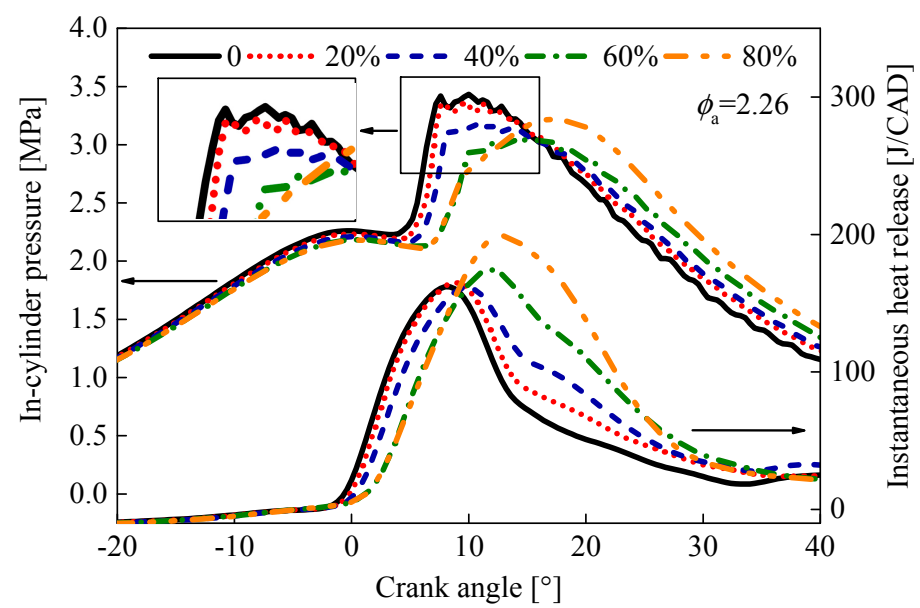

Figure 5. Comparison of in-cylinder pressure and HRR under different substitution rates at $\phi_{a}=2.26$. 


\subsection{Characteristics of BSEC}

The indicator of brake specific energy consumption (BSEC) is calculated as the reciprocal of the fuel conversion efficiency in units of $\mathrm{kJ} / \mathrm{kWh}$, indicating the fuel efficiency performance. The varying BSEC for various operating conditions at low load are shown in Figure 6. The error bars in the figures represent the standard deviation of BSEC calculated from the measurements. Although there is an improvement of the excess air ratio considering reduction of air supply, the excess air ratio still remains at a relatively lean level of 3.25 at low load. When the substitution rate is below $60 \%$, the BSEC increases with the increase of substitution rate in a slight range in accordance with findings in [27]. The difference of BSEC increase reaches $35.1 \%$ between dual-fuel $60 \%$ substitution rate and diesel-throttle opening $100 \%$ working point. A similar trend was also explored in [28] with a brake specific fuel consumption (BSFC) increase of about $36 \%$ at $26.2 \%$ of full load and $1600 \mathrm{rpm}$. Higher BSEC implies an efficiency reduction in the dual-fuel mode due to the lower flame velocity resulting from the lean mixture considering a constant energy input. At $40 \%$ substitution rate, the BSEC $(19,187.6 \mathrm{~kJ} / \mathrm{kWh})$ is increased $8.81 \%$ higher than that in the pure diesel mode $(17,633.3 \mathrm{~kJ} / \mathrm{kWh})$ due to the delayed combustion, and the trend turns to be more violent as the substitution rate is increasing at low load. Furthermore, when the substitution rate reaches $80 \%$, the BSEC is deteriorated by 3.11 times more than that of pure diesel combustion. Maintaining the substitution rate below 40\%, BSEC increasing is curbed effectively at low load.

The BSEC associated with medium load operations is exhibited in Figure 7. For the dual-fuel combustion of a substitution rate of $60 \%$ or below, thanks to the improvement of the excess air ratio $\phi_{a}=2.26$, which is more suitable for combustion, a better BSEC is achieved compared to that of pure diesel combustion at the same working point. At $40 \%$ substitution rate, the BSEC seems to get the lowest value of $15.49 \%$ lower than that in pure diesel mode with full throttle opening. Even at $80 \%$ substitution rate, the BSEC is only $49.38 \mathrm{~kJ} / \mathrm{kWh}(0.33 \%)$ higher than that of the pure diesel mode with full throttle opening. The experimental results might reveal that the way of the excess air coefficient control effectively improves the BSEC at medium load.

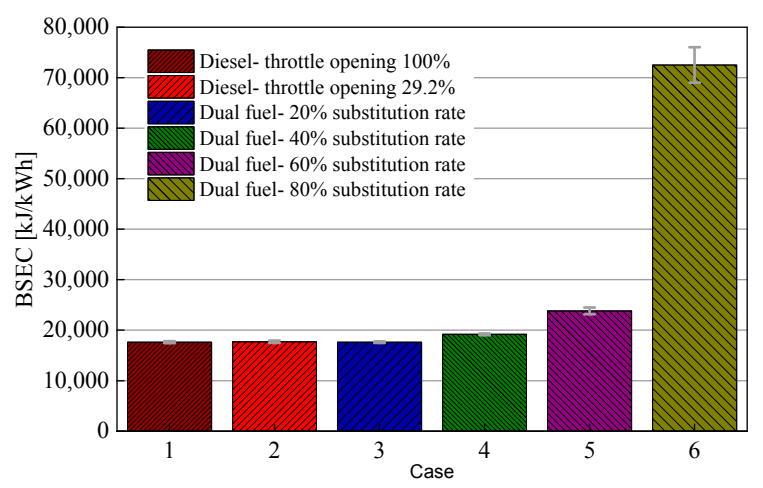

Figure 6. BSEC comparison with different substitution rates at $1600 \mathrm{rpm}, 27.1 \mathrm{~N} \cdot \mathrm{m}$.



Figure 7. BSEC comparison with different substitution rates at $1600 \mathrm{rpm}, 50.6 \mathrm{~N} \cdot \mathrm{m}$. 


\subsection{Emissions Characteristics}

It is to be noticed that the exhaust pollutants are converted into brake-specific emission values according to GB20891-2014 [20] for the test engine without any post-treatment devices. Figures 8 and 9 display the gaseous emissions at different substitution rates under low and medium load, respectively, and the same variation tendency is also found in $[28,29]$. The exhaust emissions of CO and $\mathrm{HC}$ are significantly improved with load increase at low load, which is consistent with the result in [30]. At lower excess air ratio of 2.26 combined with more pilot diesel injection promotes a faster combustion rate, therefore the emissions of $\mathrm{CO}$ and $\mathrm{HC}$ have a dramatic drop at medium load [3]. At the same time, higher levels of $\mathrm{CO}$ and $\mathrm{HC}$ emissions are observed with the increase of substitution rate under throttled operations because the mixture still remains at a lean level in agreement with the findings in [28], which reported that under conditions of $26.2 \%$ load, $1600 \mathrm{rpm}, 64.4 \%$ substitution rate and an gas-air ratio of 0.51 (an excess air ratio of 1.96) the concentration of HC reached about $9000 \mathrm{ppm}$. Possible reasons, including low chemical reactivity and consequently partial oxidation owing to the very lean mixture, too low an in-cylinder charge temperature to oxidize the premixed NG, slower combustion rate resulting from a small amount of pilot diesel and mixtures in piston crevices have been well summarized in previous studies [29,31,32]. Considering NOx formation relies on two necessary conditions, including rich air and high local temperature, the NOx emissions are determined strongly by the local zone temperature due to the lean mixture discussed herein. The NOx emissions decrease with increasing substitution rate. This is the result of more pilot diesel tending to increase the size of high-temperature zones [5]. At $80 \%$ substitution rate at low load, longer ignition delay periods resulting from more lean mixtures might produce more zones with high temperature in the cylinder compared to medium load, thereby increasing the emissions of $\mathrm{NOx}$ and $\mathrm{CO}_{2}$. The reduction of $\mathrm{CO}_{2}$ with the increase of substitution rate is due to the low carbon content in natural gas under the condition of constant energy input [33]. In terms of the characteristic soot emissions, with the increase of substitution rate the soot increases to a small extent at low load (see Figure 10). This is likely a result of the lower initial charge temperatures at low load, which also lead to relatively higher soot levels [13].
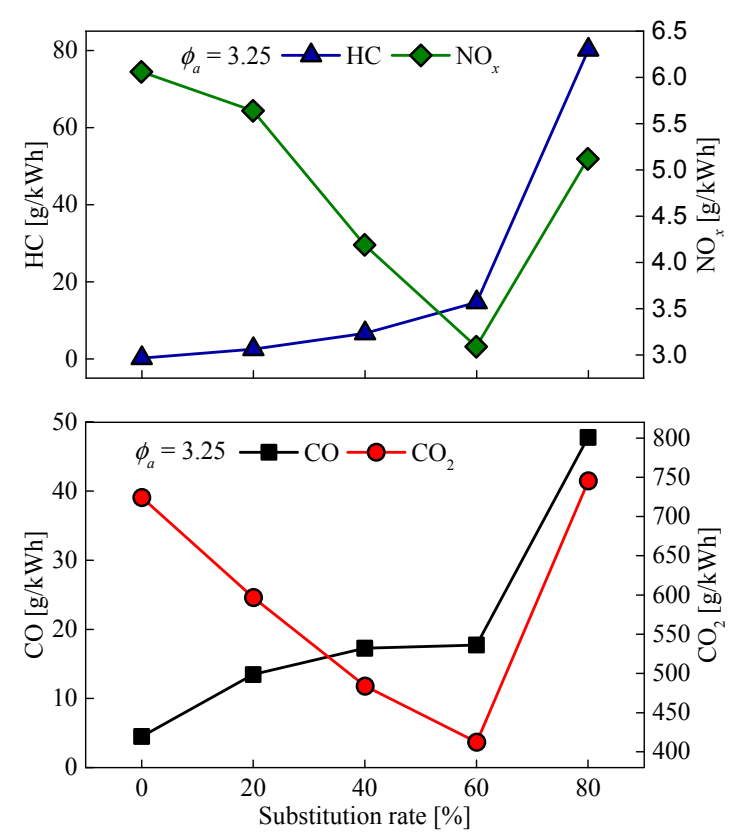

Figure 8. Comparison of emissions level with different substitution rates at $1600 \mathrm{rpm}, 27.1 \mathrm{~N} \cdot \mathrm{m}$. 


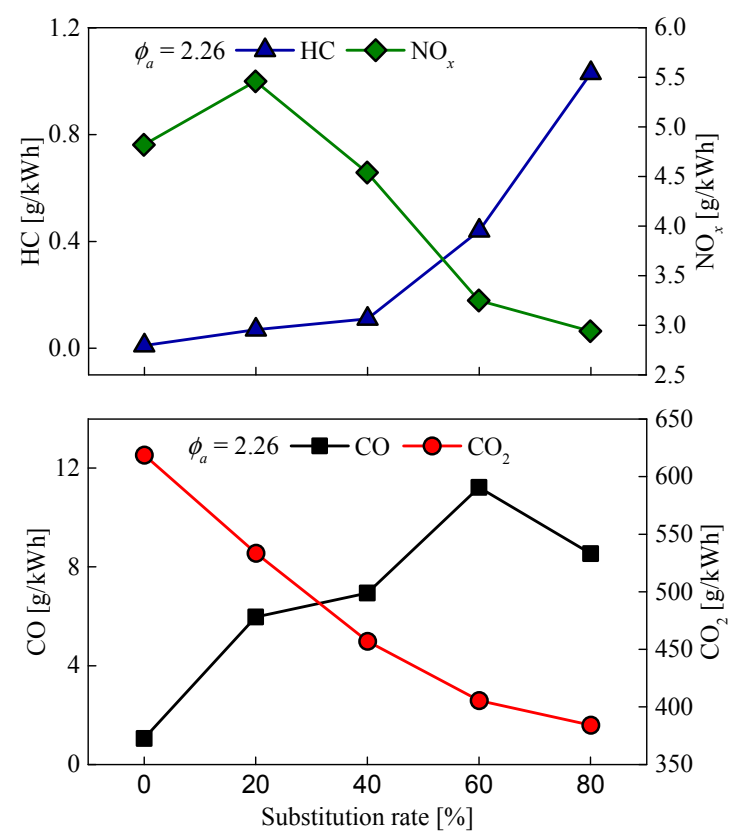

Figure 9. Comparison of emissions level with different substitution rates at $1600 \mathrm{rpm}, 50.6 \mathrm{~N} \cdot \mathrm{m}$.

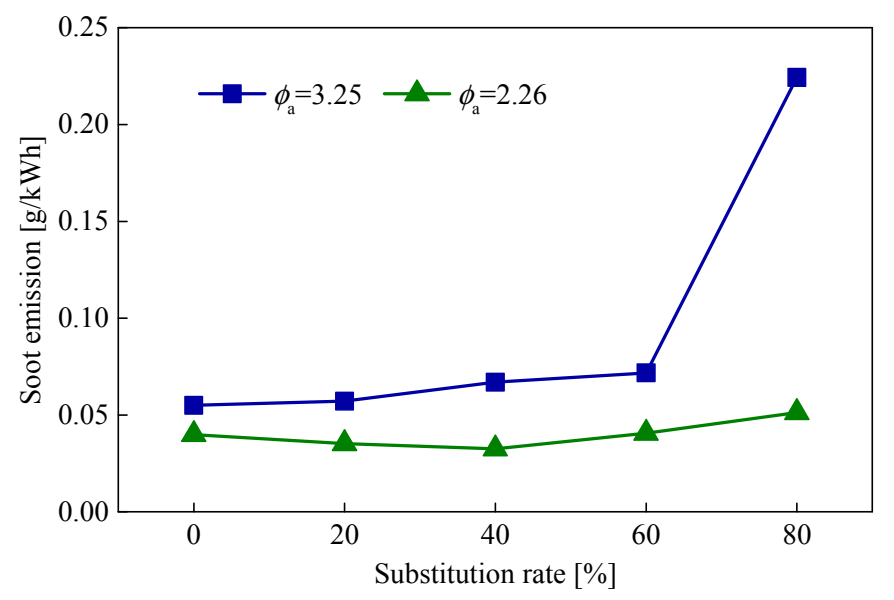

Figure 10. Comparison of soot emissions with different substitution rates.

\section{Conclusions}

The excess air coefficient control method meets the power requirements at medium and low loads and improves the NG substitution rate by controlling the air supply. The substitution rate can reach as high as $40 \%$ under low load conditions and the substitution rate can reach $80 \%$ and the average power is increased by $0.943 \mathrm{~kW}(11.1 \%)$ under medium load conditions compared to pure diesel combustion.

Better fuel efficiency is evidenced by the experimental results, especially under medium load conditions. The BSEC decreases significantly, with $15.49 \%$ lower in dual-fuel mode than that in pure diesel mode when the substitution rate equals $40 \%$, and the increase of BSEC is only $49.38 \mathrm{~kJ}(0.33 \%)$ compared to that in pure diesel mode at $80 \%$ substitution rate.

As to the emissions, the decrease of the emissions $\mathrm{CO}$ and $\mathrm{HC}$ benefits from a better excess air ratio with the reduction of air supply under medium load compared to low load, but the emissions still remain at a high level due to the lean mixture. Overall, emissions of $\mathrm{CO}_{2}$ and $\mathrm{NOx}$ decrease with increasing substitution rate as shown in earlier studies.

Through the proposed method of air supply control and pilot timing adjustment, a desirable higher substitution rate is achieved under medium and low load conditions in dual-fuel mode. This will 
help shed light on providing a feasible approach for developing a fuel supply strategy under medium and low loads for dual-fuel engines.

Author Contributions: Y.-H.P. and Y.-P.H. proposed the method of adding a throttle body at the intake pipe to control air supply, and drew up the experiment plan. J.-Y.T. and Q.-F.H. help to implement the bench test and data analysis. Y.-H.P. also was responsible for writing the paper and experiment supervision. Y.-R.H. helped with funding acquisition and provided feedback on the original draft of the paper.

Funding: This research was support of the Fujian Provincial Research Program of Industry-University Partnership (grant No. 2017H6007).

Conflicts of Interest: The authors declare no conflict of interest.

\section{References}

1. Nithyanandan, K.; Zhang, J.X.; Li, Y.Q.; Meng, X.Y.; Donahue, R.; Lee, C.F.; Dou, H.L. Diesel-Like Efficiency Using Compressed Natural Gas/Diesel Dual-Fuel Combustion. J. Energy Resour. Technol. 2016, 138. [CrossRef]

2. Carlucci, A.P.; de Risi, A.; Laforgia, D.; Naccarato, F. Experimental investigation and combustion analysis of a direct injection dual-fuel diesel-natural gas engine. Energy 2008, 33, 256-263. [CrossRef]

3. Manns, H.; Brauer, M.; Dyja, H.; Beier, H.; Lasch, A. Diesel CNG-the Potential of a Dual Fuel Combustion Concept for Lower $\mathrm{CO}_{2}$ and Emissions. SAE Tech. Pap. 2015. [CrossRef]

4. Sahoo, B.B.; Sahoo, N.; Saha, U.K. Effect of engine parameters and type of gaseous fuel on the performance of dual-fuel gas diesel engines-A critical review. Renew. Sustain. Energy Rev. 2009, 13, 1151-1184. [CrossRef]

5. Srinivasan, K.K.; Krishnan, R.S.; Midkiff, K.C. Improving low load combustion, stability, and emissions in pilot-ignited natural gas engines. Proc. Inst. Mech. Eng. Part D J. Automob. Eng. 2006, 220, 229-239. [CrossRef]

6. Yang, B.; Xi, C.X.; Wei, X.; Zeng, K.; Lai, M.C. Parametric investigation of natural gas port injection and diesel pilot injection on the combustion and emissions of a turbocharged common rail dual-fuel engine at low load. Appl. Energy 2015, 143, 130-137. [CrossRef]

7. Yousefi, A.; Guo, H.S.; Birouk, M. An experimental and numerical study on diesel injection split of a natural gas/diesel dual-fuel engine at a low engine load. Fuel 2018, 212, 332-346. [CrossRef]

8. Belgiorno, G.; Di, B.G.; Beatrice, C. Parametric study and optimization of the main engine calibration parameters and compression ratio of a methane-diesel dual fuel engine. Fuel 2018, 222, 821-840. [CrossRef]

9. Hutter, R.; Ritzmann, J.; Elbert, P.; Onder, C. Low-Load Limit in a Diesel-Ignited Gas Engine. Energies 2017, 10, 1450. [CrossRef]

10. Ryu, K. Effects of pilot injection timing on the combustion and emissions characteristics in a diesel engine using biodiesel-CNG dual fuel. Appl. Energy 2013, 111, 721-730. [CrossRef]

11. Yousefi, A.; Birouk, M. An Investigation of Multi-Injection Strategies for a Dual-Fuel Pilot Diesel Ignition Engine at Low Load. J. Energy Resour. Technol. 2016, 139, 012201. [CrossRef]

12. Di Blasio, G.; Belgiorno, G.; Beatrice, C.; Fraioli, V.; Migliaccio, M. Experimental evaluation of compression ratio influence on the performance of a dual-fuel methane-diesel light-duty engine. SAE Int. J. Engine 2015, 8, 2253-2267. [CrossRef]

13. Papagiannakis, R.G.; Hountalas, D.T.; Krishnan, S.R.; Srinivasan, K.K.; Rakopoulos, D.C. Numerical Evaluation of the Effects of Compression Ratio and Diesel Fuel Injection Timing on the Performance and Emissions of a Fumigated Natural Gas-Diesel Dual-Fuel Engine. J. Energy Eng. 2016, 142, E4015015. [CrossRef]

14. Shu, J.; Fu, J.; Liu, J.; Zhang, L.; Zhao, Z. Experimental and computational study on the effects of injection timing on thermodynamics, combustion and emission characteristics of a natural gas (NG)-diesel dual fuel engine at low speed and low load. Energy Convers. Manag. 2018, 160, 426-438. [CrossRef]

15. Wang, Z.; Zhao, Z.; Wang, D.; Tan, M.; Han, Y.; Liu, Z.; Dou, H. Impact of pilot diesel ignition mode on combustion and emissions characteristics of a diesel/natural gas dual fuel heavy-duty engine. Fuel 2016, 167, 248-256. [CrossRef]

16. Chatlatanagulchai, W.; Yaovaja, K.; Rhienprayoon, S.; Wannatong, K. Air-fuel ratio regulation with optimum throttle opening in diesel-dual-fuel engine. SAE Pap. 2010. [CrossRef]

17. Fu, Y.; Xiao, B.; Zhang, C.; Liu, J.; Fang, J. A new method for on-line estimation of the piston maximum temperature in diesel-nature gas dual fuel engine. J. Eng. Gas Turbines Power 2018, 140, 061507. [CrossRef] 
18. Pedrozo, V.B.; May, I.; Lanzanova, T.D.M.; Zhao, H. Potential of internal EGR and throttled operation for low load extension of ethanol-diesel dual-fuel reactivity controlled compression ignition combustion on a heavy-duty engine. Fuel 2016, 179, 391-405. [CrossRef]

19. Henham, A.; Makkar, M.K. Combustion of simulated biogas in a dual-fuel diesel engine. Energy Convers. Manag. 1998, 39, 2001-2009. [CrossRef]

20. Ministry of Environmental Protection, State Administration of Quality Supervision, Inspection and Quarantine. Limits and Measurement Methods for Exhaust Pollutants form Diesel Engines of Non-Road Mobile Machinery (CHINA III,IV); China Environmental Science Press: Beijing, China, 2014.

21. Bedoya, I.D.; Arrieta, A.A.; Cadavid, F.J. Effects of mixing system and pilot fuel quality on diesel-biogas dual fuel engine performance. Bioresour. Technol. 2009, 100, 6624-6629. [CrossRef] [PubMed]

22. Mitchell, R.; Olsen, D.B. Extending Substitution Limits of a Diesel-Natural Gas Dual Fuel Engine. J. Energy Resour. Technol. 2018, 140, 052202. [CrossRef]

23. Wang, J.X.; Shuai, S.J. Automotive Engine Fundamentals; Tsinghua University Press: Beijing, China, 2011.

24. Maxey, C.; Kalaskar, V.; Kang, D.; Boehman, A. Impact of supplemental natural gas on engine efficiency, performance, and emissions. SAE Tech. Pap. 2013, 2, 79-90. [CrossRef]

25. Dahodwala, M.; Joshi, S.; Koehler, E.W.; Franke, M. Investigation of diesel and CNG combustion in a dual fuel regime and as an enabler to achieve RCCI combustion. SAE Tech. Pap. 2014, 2014. [CrossRef]

26. Papagiannakis, R.G.; Rakopoulos, C.D.; Hountalas, D.T.; Rakopoulos, D.C. Emission characteristics of high speed, dual fuel, compression ignition engine operating in a wide range of natural gas/diesel fuel proportions. Fuel 2010, 89, 1397-1406. [CrossRef]

27. Sombatwong, P.; Thaiyasuit, P.; Pianthong, K. Effect of Pilot Fuel Quantity on the Performance and Emission of a Dual Producer Gas Diesel Engine. Energy Procedia 2013, 34, 218-227. [CrossRef]

28. Egúsquiza, J.C.; Braga, S.L.; Braga, C.V.M. Performance and gaseous emissions characteristics of a natural gas/diesel dual fuel turbocharged and after-cooled engine. J. Braz. Soc. Mech. Sci. Eng. 2009, 31, 142-150. [CrossRef]

29. Papagiannakis, R.G.; Hountalas, D.T. Experimental investigation concerning the effect of natural gas percentage on performance and emissions of a DI dual fuel diesel engine. Appl. Therm. Eng. 2003, 23, 353-365. [CrossRef]

30. Uma, R.; Kandpalb, T.C.; Kishorea, V.V.N. Emission characteristics of an electricity generation system in diesel alone and dual fuel modes. Biomass Bioenergy 2004, 27, 195-203. [CrossRef]

31. Yousefi, A.; Birouk, M.; Guo, H. An experimental and numerical study of the effect of diesel injection timing on natural gas/diesel dual-fuel combustion at low load. Fuel 2017, 203, 642-657. [CrossRef]

32. Liu, J.; Zhang, X.; Wang, T.; Zhang, J.B.; Wang, H.W. Experimental and numerical study of the pollution formation in a diesel/CNG dual fuel engine. Fuel 2015, 159, 418-429. [CrossRef]

33. Vávra, J.; Bortel, I.; Takáts, M.; Diviš, M. Emissions and performance of diesel-natural gas dual-fuel engine operated with stoichiometric mixture. Fuel 2017, 208, 722-733. [CrossRef] 